\title{
Effects of peeling and steam-heating treatment on basic properties of two types of bamboo culms (Phyllostachys makinoi and Phyllostachys pubescens)
}

\author{
Min jay Chung ${ }^{1,2} \cdot$ Sheng Yang Wang ${ }^{2,3}$
}

Received: 13 March 2017/ Accepted: 10 June 2017/Published online: 25 July 2017

(C) The Japan Wood Research Society 2017

\begin{abstract}
Epidermal peeling (EPT) and steam-heating (SHT) treatments are two widely processing methods in bamboo industry. Moso bamboo (Phyllostachys pubescens Mazel) and makino bamboo (Phyllostachys makinoi Hayata) are important economical bamboo species in Taiwan and China. The subject of this study was to access the changes of chemical and mechanical properties in moso and makino bamboo culms, which were collected from Taiwan and China after EPT and SHT. As regard to chemical properties, the amounts of extractives and ash were increased both in moso and makino bamboos after EPT and SHT. In contrast, the contains of holocellulose and $\alpha$-cellulose were decreased after EPT and SHT for two bamboos. Moso bamboo collected from China contained the lowest cellulose content but the highest amount of hemicellulose by SHT. The lignin contents of all samples were no significant different after SHT, and it might due to the structure of lignin did not destroy at $120^{\circ} \mathrm{C}$. For the mechanical properties, the density of all makino and moso bamboo samples was reduced after SHT; moreover, the decreasing trend of density was similar to the reducing of holocellulose, $\alpha$-cellulose, hemicellulose, and equilibrium moisture content (EMC). All bamboo samples without EPT presented the highest modulus of elasticity (MOE) and
\end{abstract}

Sheng Yang Wang

taiwanfir@dragon.nchu.edu.tw

1 Experimental Forest, National Taiwan University, No. 12, Section 1, Chien-Shan Road, Chu-Shan,

Nantou Hsien 55750, Taiwan

2 Department of Forestry, National Chung-Hsing University, No. 250, Kou Kung Road, Taichung 402, Taiwan

3 Agricultural Biotechnology Research Center, Academia Sinica, Taipei 128, Taiwan modulus of rupture (MOR) whether SHT or not. Both MOE and MOR of all bamboo samples were decreased after SHT. The integrity of the bamboo skin is important for the dimensional stability of the bamboo, and the water absorption ability would be increased after EPT; however, SHT decreased the water absorption of bamboo.

Keywords Phyllostachys pubescens - Phyllostachys makinoi $\cdot$ Epidermal peeling treatment $\cdot$ Steam-heating treatment $\cdot$ Chemical properties $\cdot$ Mechanical properties

\section{Introduction}

Bamboo is a monocotyledonous plant; there are around 2000 million hectares of bamboo forests worldwide, of which $70 \%$ are located in Asia [1]. Bamboo possessed many advantages such as rapid growth, good elasticity, short-term renewal, etc. Appropriate processing with bamboo, including physical, chemical, and mechanical treatments, bamboo culms can be commonly used as material for making agricultural appliances, furniture, paper, natural fiber, activated carbon, and granulated fuel. Thus, the bamboo utilization has been getting attention all over the world. Bamboo is also a renewable biomaterial, which has a good tensile strength, longitudinal compression strength, and flexural strength properties. Because of the above advantages, bamboo is the excellent raw material for being processed into structural materials such as plywood, particleboard, and bamboo scrimber [2]. However, bamboo is similar to other lignocellulosic materials with high water content and hydrophilicity; meanwhile, it also has several disadvantages, e.g., decay, deformation, durability, and dimensional stability [3].

To reduce negative aspects of lignocellulosic materials, chemical processes, such as etherification, esterification, and 
phenylation as well as heat treatment methods, have been proposed for improving the physical properties of timber materials [4, 5]. Spruce wood (Picea abies) had degraded hemicellulose, softened lignin, and hence reduced hydrophilicity of cellulose after treated with high temperature [6]. The other similar effect of heat treatment was found to improve hydrophobicity of spruce wood [7], and ameliorating the susceptibility of wood to microbial decomposition component, thus enhancing their dimensional stability and durability [8]. Furthermore, studies confirmed that the contents of major chemical constituents, including cellulose, hemicellulose, lignin of moso bamboo (Phyllostachys pubescens), and spruce wood, were reduced by heat treatment, and it significantly affected durability, surface properties, physical properties, and mechanical properties of wooden materials $[9,10]$. Current trend of market of bamboo industry and development inclined toward production of glued laminated timber, which is also called glulam. To fulfill the performance requirements, there has been intense research on varieties of bamboo composites. To obtain a standardized integrated element and enhance good gluing properties of bamboo composites, two side planing-machine and peeled machine are widely applied to remove bamboo epidermis recently; however, the different integrated bamboo elements would be obtained and causing the different properties of bamboo composites [11].

This study examined the effects of epidermal peeling (EPT) and steam-heating (SHT) treatments on chemical and mechanical properties of bamboo. Two common economical and popular bamboo species grown in Taiwan and China, namely, moso bamboo and makino bamboo (Phyllostachys makinoi), were studied and compared in terms of their chemical properties, physical properties, and mechanical strength. We believe that the results obtained in this study are not only contributed to more thorough understanding on properties of peeled and steam-heated treatment bamboo, but also provides useful information for development and applications of bamboo-based engineering materials.

\section{Materials and methods}

\section{Bamboo samples}

Three-year-old moso bamboo and makino bamboo culms were collected from the Experimental Forest of National Taiwan University in Nan-Tou County, Taiwan in October 2014. In addition, 3-year-old moso bamboo samples were also collected from Lin'an County, Zhejiang Province, China. All bamboo culms were cut into strips of $2 \mathrm{~cm}$ wide by circular saw machine and each test condition is nine bamboo specimens from different bamboo culms. In particular, moso bamboo samples were divided into two types, i.e., unpeeled/with epidermis and peeled/without epidermis. To obtain better reagent penetration and chemical reaction in the post-treatment, it is necessary to remove the dirt and siliceous wax layers from bamboo surfaces. Thus, all bamboo samples were pre-treated with an alkaline solution containing $2 \%$ potassium hydroxide $(\mathrm{KOH})$ at $100{ }^{\circ} \mathrm{C}$ for $30 \mathrm{~min}$ and then oven-dried at $80^{\circ} \mathrm{C}$. For SHT, bamboo strips were placed in a steam-heating furnace at $120^{\circ} \mathrm{C}$ for $6 \mathrm{~h}$. Prior to the experiments, all specimens were conditioned in a controlled environment with temperature at $20^{\circ} \mathrm{C}$ and relative humidity $(\mathrm{RH})$ at $65 \%$ for 2 weeks. Table 1 summarizes the codes of sample and treatment conditions for eight examined bamboo specimens.

\section{Chemical properties analysis}

All chemical analyses were conducted in accordance with standard methods of the American Society for Testing and Materials (ASTM) (Table 2) [12-17]. Hemicellulose content was calculated by subtracting cellulose content from holocellulose content. The amounts were expressed as a percentage of the initial oven-dry weight.

\section{Mechanical strength analysis}

The bamboo specimens were tested using the ASTM method standard D-1037 [18] to exam the mechanical strength. The previously conditioned $20 \times 2 \times 1 \mathrm{~cm}$ (length $\times$ width $\times$ thickness) bamboo specimens were tested in a three-point bending experiment conducted with a span of $144 \mathrm{~mm}$ and a displacement-controlled testing speed of $3 \mathrm{~mm} / \mathrm{min}$. In the test, the specimens were intentionally placed, so that the bamboo outer layer was on the tension side. The static bending test was carried out using a Shimadzu UH-10A (Tokyo, Japan) universal-type testing machine according to the center-loading method for specimens. A concentrated bending load was applied at the center with a span 15 times the thickness of the specimen. Both modulus of elasticity (MOE) and modulus of rupture (MOR) were calculated from load to deflection curves.

\section{Dimensional stability}

The bamboo specimens were tested using the ASTM method standard D-1037 [18] to determine volumetric swelling, thickness swelling, and water absorption. The previously conditioned $20 \times 2 \times 1 \mathrm{~cm}$ specimens were dried at $103 \pm 2{ }^{\circ} \mathrm{C}$ before measuring the weight and volume. Initial thickness at the middle of the test specimen was first measured with a micrometer. Then, all test specimens were 
Table 1 Conditions and codes for experimental bamboo specimens

\begin{tabular}{|c|c|c|c|c|c|}
\hline No. & Collection site & Species & Epidermis & Steam-heating treatment (SHT) & Code \\
\hline 1 & Taiwan & Makino bamboo & Yes & No & $\mathrm{TPmE}$ \\
\hline 2 & & & & Yes & $\mathrm{TPmE}-\mathrm{H}$ \\
\hline 3 & & Moso bamboo & Yes & No & TMosoE \\
\hline 4 & & & & Yes & TMosoE-H \\
\hline 5 & & & No & No & TMoso \\
\hline 6 & & & & Yes & TMoso-H \\
\hline 7 & China & Moso bamboo & No & No & CMoso \\
\hline 8 & & & & Yes & CMoso-H \\
\hline
\end{tabular}

Table 2 Standard methods used for chemical analysis of bamboo culms

\begin{tabular}{llll}
\hline Properties & Replicates & Standard & References \\
\hline Alcohol-benzene extractives & 3 & ASTM D 1107-56 (reapproved 1983) & {$[12]$} \\
Holocellulose & 3 & ASTM D 1104-56 (reapproved 1978) & {$[13]$} \\
$\alpha$-cellulose & 3 & ASTM D 1103-60 (reapproved 1977) & {$[14]$} \\
Klason lignin & 3 & ASTM D 1106-56 (reapproved 1977) & {$[15]$} \\
Acid-soluble lignin & 3 & ASTM D 1106-96 (reapproved 2001) & {$[16]$} \\
Ash content & 3 & ASTM D 1102-84 (reapproved 2001) & {$[17]$} \\
\hline
\end{tabular}

placed in parallel $30 \mathrm{~mm}$ under water and soaked for 2 and $24 \mathrm{~h}$ before the thickness was measured again.

\section{Equilibrium moisture content (EMC)}

According to the testing procedure of ASTM D1037 [18], the $20 \times 2 \times 1 \mathrm{~cm}$ specimens were placed in a conditioning chamber at $20 \pm 3{ }^{\circ} \mathrm{C}$ and $50 \pm 2 \%$ RH for 4 weeks before taking weight and volume measurements. The specimens were then kept at $20 \pm 3{ }^{\circ} \mathrm{C}$ and $90 \pm 5 \% \mathrm{RH}$ for 4 more weeks and measured again. The EMC was evaluated for the specimens before and after the EPT and SHT.

\section{Statistical analysis}

All multiple comparisons of physical and mechanical properties were subjected to Tukey's test and analysis of variance (ANOVA). Significant differences between mean values (standard error, SE) of control and experimental specimens were determined using the Tukey's multiple range test.

\section{Results and discussion}

\section{Chemical properties analysis}

\section{Extractives content}

It has been reported that the alcohol-benzene extractives in most lignocellulosic materials comprise waxes, fats, resins, rubber, and water-soluble substances, all of which can affect gluing and coating process; it also influences the dimensional stability and durability of lignocellulosic materials [19]. Hence, assessing the extractives contents of bamboo would shed light on the suitability of their applications. As shown in Fig. 1, there was increasing the trend in alcohol-benzene extractives after SHT, and it indicated changes in chemical composition after SHT. Moreover, extractives contain of untreated with heat and SHT specimens were shown in the order of $\mathrm{TP} m \mathrm{E}<\mathrm{TMo}-$ soE $<$ TMoso $<$ CMoso (extractives values were 5.2, 7.2, 8.8, and 9.8\%, respectively) and $\mathrm{TPmE}-\mathrm{H}<\mathrm{TMosoE}-$ $\mathrm{H}<\mathrm{TMoso}-\mathrm{H}<\mathrm{CMoso}-\mathrm{H}$ (extractives values were 7.1, 7.7, 9.3, and $10.1 \%$, respectively); SHT moso bamboo collected from China (CMoso-H) contained the highest amount of extractives. However, there was no significant difference in extractives between species from Taiwan and China, which epidermis had been removed. Furthermore, moso bamboo (TMosoE and TMosoE-H were 7.2 and $7.7 \%)$ contained more extractives than makino bamboo (TPmE and TPmE-H were 5.2 and 7.1\%), and EPT specimens had higher extractives than those with intact epidermis $(p>0.05)$. Taken together, our results revealed that EPT and SHT contribute to increase extractives contents of bamboos. Our findings are consistent with reported previously that thermal treatment affects the fundamental chemical properties of plantation woods and moso bamboo [20, 21]; heating treatment wood and bamboo could increase the amounts of extractives. Candelier and his coworkers attributed changes in chemical composition of wood to thermal degradation of polysaccharides under high-temperature heat treatment [22]. Boonstra and 
Fig. 1 Amounts of extractives of eight different bamboo specimens using benzenealcohol extraction [results are mean $\pm \mathrm{SE}, n=9$; different letters $\mathrm{a}, \mathrm{b}, \mathrm{c}$, and $\mathrm{d}$ in a given column indicate significant differences at the 0.05 level by Tukey's test and analysis of variance (ANOVA)]

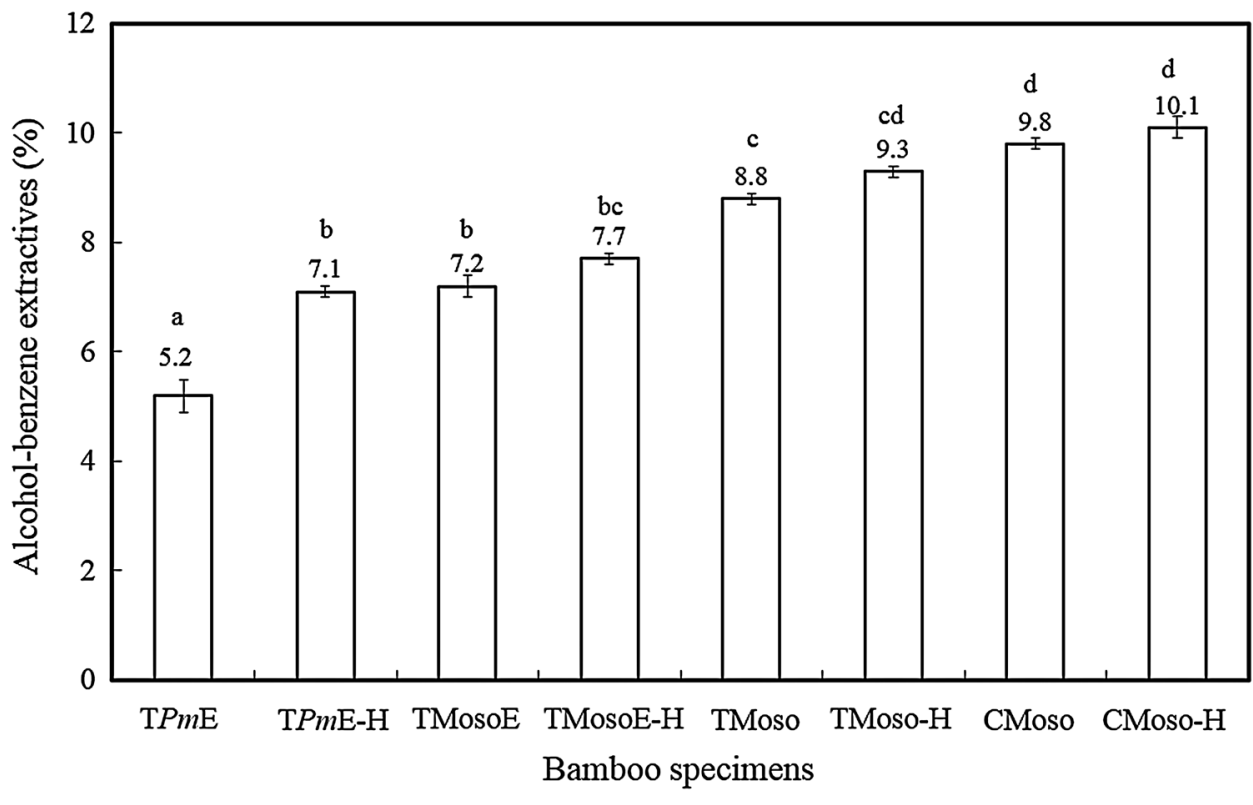

Tjeerdsma also demonstrated that a two-stage heat treatment led to depolymerization of carbohydrates and especially of hemicelluloses, which in turn caused increase in relative lignin percentage [23].

\section{Holocellulose, $\alpha$-cellulose, and hemicellulose contents}

Cellulose is the main constituent of cell walls of bamboo culms; it significantly influence on the physical and mechanical properties of bamboo. Figure 2 shows the holocellulose, $\alpha$-cellulose, and hemicellulose contents in the eight bamboo specimens. Cellulose contents for all specimens were decreased after SHT $(p>0.05)$; moreover, holocellulose and $\alpha$-cellulose contents of untreated and SHT specimens were in the order of CMoso $<$ TMoso $<$ TMosoE $<$ TPmE and CMoso-H $<$ TMoso-H $<$ TMosoE$\mathrm{H}<\mathrm{TPmE}-\mathrm{H}$, respectively. SHT moso bamboo collected from China (CMoso-H) containing the least amount of holocellulose $(64.2 \%)$ and $\alpha$-cellulose $(42.8 \%)$. The results obtained in this study revealed that makino bamboo (TPmE and TPmE-H) contained more holocellulose (71.1 and $69.2 \%$ ) and $\alpha$-cellulose contents (57.7 and 56.3\%) than moso bamboo; moso bamboo collected from Taiwan with epidermis intact (TMosoE and TMosoE-H) had higher holocellulose (69.1 and 66.4\%) and $\alpha$-cellulose (52.5 and 51.3\%) contents than those without. Based on the anatomical properties of bamboo culms, Li and his coworkers demonstrated that holocellulose content decreased from the outer to the inner radial layer, but was not significantly different between the middle and inner layers; meanwhile, $\alpha$-cellulose differed greatly across radial layers of the culm in the basal portion of the 3-year-old moso bamboo and consistently decreased from the outer to inner layers [24]. Besides, moso bamboo from Taiwan (TMoso and TMoso-H) contained more holocellulose (68.1 and 65.2\%) and $\alpha$-cellulose (47.9 and 45.9\%) than that from China; however, there was no significant different in cellulose contents after EPT.

In contrast, hemicellulose content showed contrary trends with holocellulose and $\alpha$-cellulose that were CMoso $>$ TMoso $>$ TMosoE $>$ TPmE for untreated specimens and CMoso-H $>$ TMoso-H $>$ TMosoE-H $>$ TPmE-H for SHT ones, with untreated moso bamboo collected from China (CMoso) containing the highest amount of hemicellulose $(23.1 \%)$. Moreover, makino bamboo contained less hemicellulose than moso bamboo with or without epidermis. In conclusion, the results indicated that EPT and SHT contributed to reduce cellulose contents. These findings were similar to those reported that hemicellulose had low thermal stability and coursed most degradation by heat treatment. Pyrolysis of hemicellulose would reduce cellulose content, thus undermining the strength of lignocellulosic material [10, 23]. The possible reason for this phenomenon might due to hemicellulose is one kind of plant cell-wall polysaccharides, which linked to lignin by covalent bonds and interconnected together with cellulose by physical intermixing. Previous studies also have demonstrated a relationship between the degradation of hemicellulose components, such as arabinose and mannose, and wood strength losses. The significant reduction in strength observed during incipient decay is, therefore, to be due to hemicellulose decomposition [25].

\section{Lignin content}

Besides cellulose content, lignin content also significantly affects on strength of timber; for example, the compressive 
Fig. 2 Holocellulose, $\alpha$ cellulose, and hemicellulose contents $(\%)$ of eight different bamboo specimens after EPT and SHT [results are mean $\pm \mathrm{SE}, n=9$; different letters $\mathrm{a}, \mathrm{b}, \mathrm{c}$, and $\mathrm{d}$ in a given column indicate significant differences at the 0.05 level by Tukey's test and analysis of variance (ANOVA)]

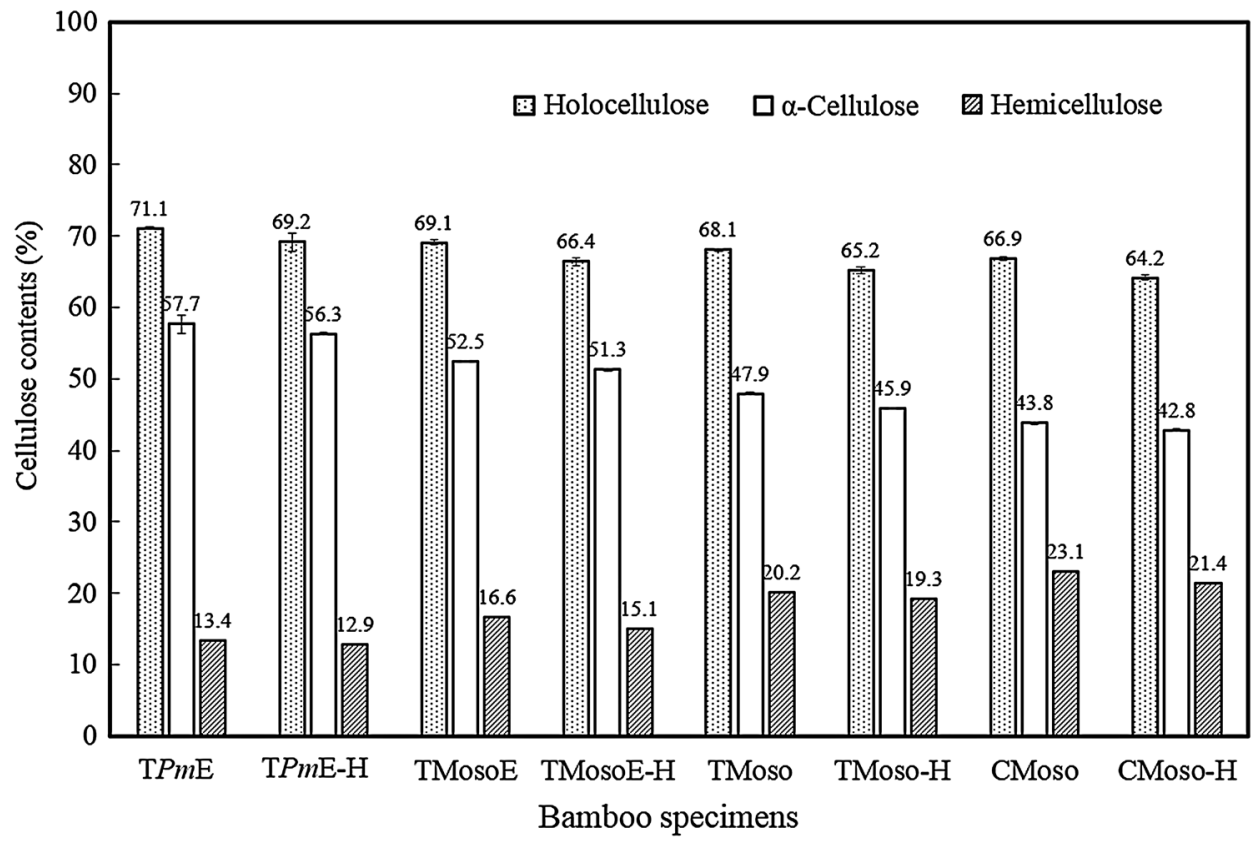

strength of wood is correlated with lignin content [24]. Table 3 presents the Klason lignin and acid-soluble lignin contents of bamboo specimens after different treatments. SHT samples of all bamboo species contained slightly less Klason lignin and acid-soluble lignin than untreated ones. The range of Klason lignin contents was between 20 and $23 \%$, while acid-soluble lignin contents were from 1.4 to $2.2 \%$. It is worth noting that moso bamboo without EPT revealed the highest Klason lignin content $(23.1 \%$ in TMosoE and $23.0 \%$ in TMosoE-H), while EPT group contained the least amounts of Klason lignin $(20.0 \%$ in TMoso and $19.7 \%$ in TMoso-H); the results implied that the presence of higher lignin concentrates in the outer layer and epidermis of the bamboo culms. There was no difference in Klason lignin contents between specimens from

Table 3 Klason lignin and acid-soluble lignin contents (\%) of eight different treatment bamboo specimens [results are mean \pm SE (standard error), $n=9$ ]

\begin{tabular}{llll}
\hline No. & Samples & Klason lignin & Acid-soluble lignin \\
\hline 1 & TPmE & $22.3 \pm 0.2^{\mathrm{ab}}$ & $1.7 \pm 0.0$ \\
2 & TPmE-H & $21.8 \pm 0.3^{\mathrm{b}}$ & $1.6 \pm 0.0$ \\
3 & TMosoE & $23.1 \pm 0.2^{\mathrm{a}}$ & $1.6 \pm 0.1$ \\
4 & TMosoE-H & $23.0 \pm 0.5^{\mathrm{a}}$ & $1.4 \pm 0.1$ \\
5 & TMoso & $20.0 \pm 0.4^{\mathrm{c}}$ & $1.9 \pm 0.1$ \\
6 & TMoso-H & $19.7 \pm 0.1^{\mathrm{c}}$ & $1.7 \pm 0.1$ \\
7 & CMoso & $21.2 \pm 0.2^{\mathrm{b}}$ & $2.2 \pm 0.0$ \\
8 & CMoso-H & $20.8 \pm 0.4^{\mathrm{bc}}$ & $2.2 \pm 0.1$ \\
\hline
\end{tabular}

Different letters a, b, and $\mathrm{c}$ in a given column indicate significant differences at the 0.05 level by Tukey's test and analysis of variance (ANOVA)
Taiwan and those from China $(p<0.05)$; however, moso bamboo collected from China was found to have significant higher acid-soluble lignin content than bamboo from Taiwan.

Results shown in Table 3 revealed that SHT had minor effect on Klason lignin contents of both moso bamboo and makino bamboos. It means that SHT at $120{ }^{\circ} \mathrm{C}$ for $6 \mathrm{~h}$ did not depredated or re-polymerization reaction in bamboo specimens, leading to insignificant changes in lignin contents. Distinct effect on lignin contents was observed after heat treatment at higher temperatures above $120^{\circ} \mathrm{C}$ [26]. Apparent increasing of the amount of Klason lignin after SHT at 180 and $220^{\circ} \mathrm{C}$ might due to the ongoing removal of hemicelluloses during thermal degradation [27]. Organic acids released from hemicelluloses also caused cleavage of the lignin-polysaccharide complex (LCC), while condensation reaction enabled polymerization of lignin components, thus increasing its relative content [27].

\section{Ash content}

Figure 3 presents ash contents of the eight different bamboo specimens. The ash contents were reduced after SHT. Thermal treatment would cause wood deterioration and mass loss, which caused higher ash content. Moreover, ash contents of untreated and SHT specimens were in the order of $\mathrm{TMosoE}<\mathrm{TPmE}<\mathrm{TMoso}<\mathrm{CMoso}$ and $\mathrm{TPmE}-$ $\mathrm{H}<$ TMosoE-H $<$ TMoso- $\mathrm{H}<$ CMoso- $\mathrm{H}, \quad$ respectively, with steam-heated moso bamboo collected from China (CMoso-H) contained the highest amount of ash (1.65\%). However, the ash content between specimens from Taiwan 
Fig. 3 Ash contents (\%) of eight different bamboo specimens [results are letters $\mathrm{a}, \mathrm{b}, \mathrm{c}, \mathrm{d}$, and $\mathrm{e}$ in a given column indicate significant differences at the 0.05 level by Tukey's test and analysis of variance (ANOVA)] mean $\pm \mathrm{SE}, n=9$; different

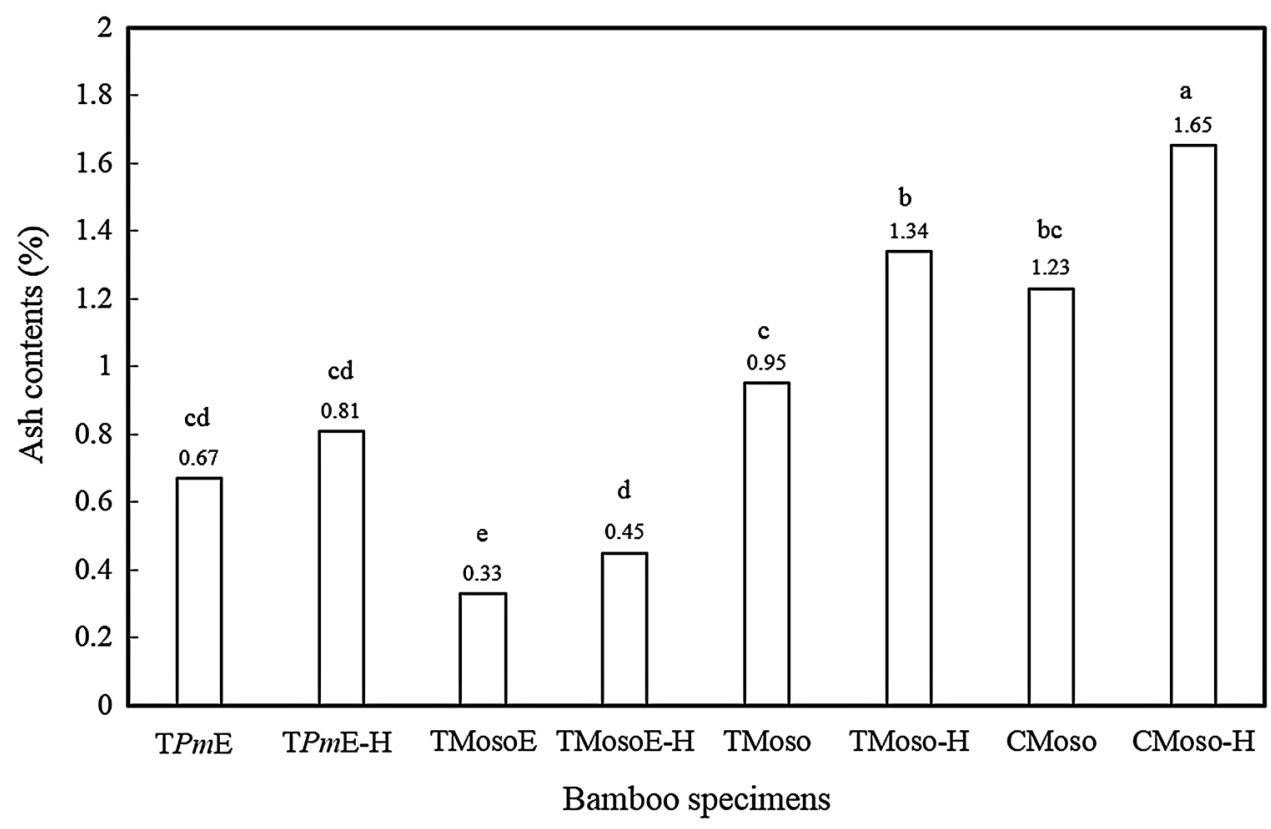

Fig. 4 Density of eight different bamboo specimens at $65 \% \mathrm{RH}$ [results are mean $\pm \mathrm{SE}, n=9$; different letters $\mathrm{a}, \mathrm{b}$, and $\mathrm{c}$ in a given column indicate significant differences at the 0.05 level by Tukey's test and analysis of variance (ANOVA)]

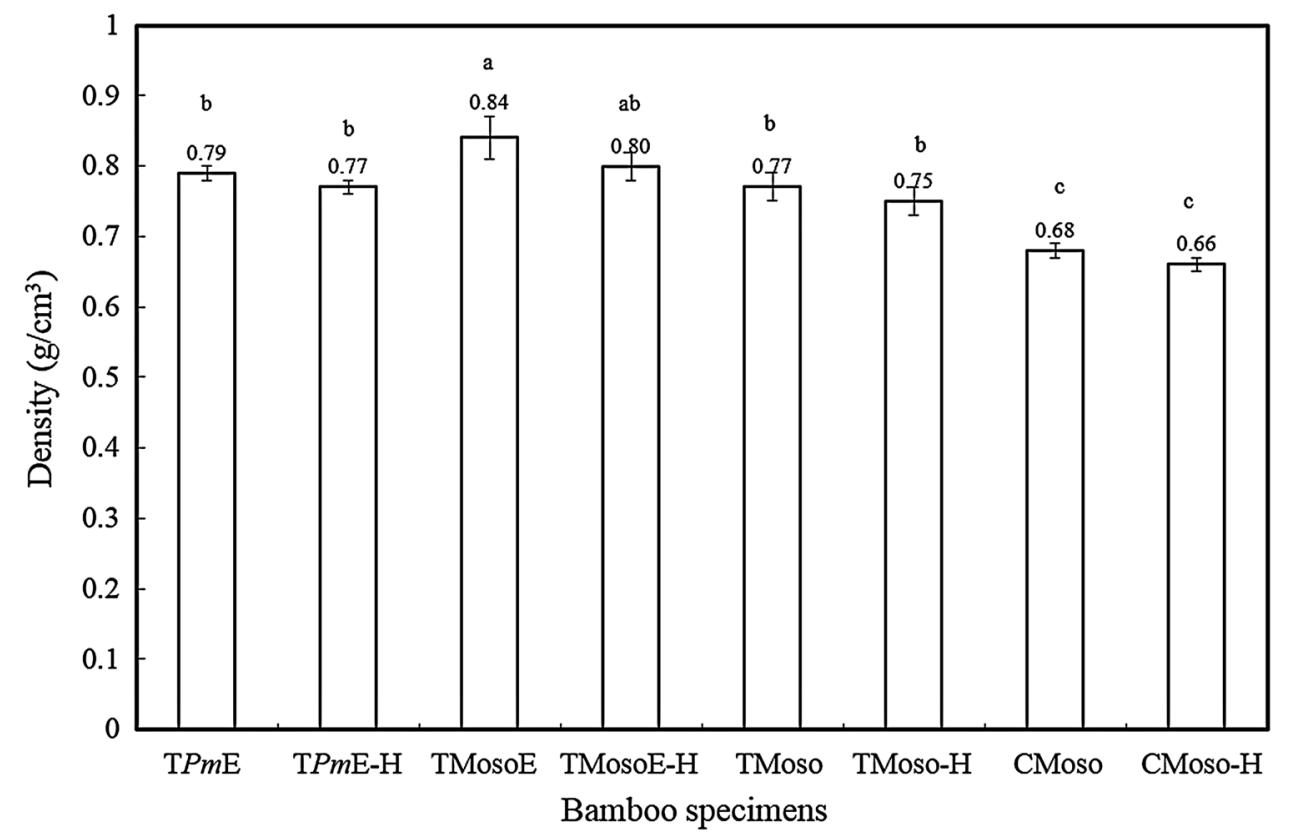

and China was no distinction after EPT. Furthermore, moso bamboo (TMoso, CMoso, TMoso-H, and CMoso-H were $0.95,1.23,1.34$, and $1.65 \%$, respectively) had higher ash content than makino bamboo ( $\mathrm{TP} m \mathrm{E}$ and $\mathrm{TPmE}-\mathrm{H}$ were 0.67 and 0.81 , respectively), with the exception of without EPT moso bamboo specimens (TMosoE and TMosoE-H were 0.33 and $0.45 \%$, respectively). Both EPT and SHT would increase ash content, which undermines timber quality. These findings were consistent with those reported results that mass loss increased in moso bamboo after heat treatment [21].

\section{Physical properties analysis}

\section{Density}

Figure 4 shows the density of eight different bamboo specimens under $65 \% \mathrm{RH}$. The densities were decreased in all samples after SHT. It indicated that SHT at $120{ }^{\circ} \mathrm{C}$ for 6 $\mathrm{h}$ would decrease bamboo density. Moreover, densities of untreated and SHT specimens were in the order of CMoso $<\mathrm{TMoso}<\mathrm{TPmE}<\mathrm{TMosoE}$ (density values were 0.68, 0.77, 0.79, and $0.84 \mathrm{~g} / \mathrm{cm}^{3}$, respectively) and CMoso- 
Fig. 5 EMC (\%) of eight different bamboo specimens [results are mean \pm SE, $n=9$; different letters $\mathrm{a}, \mathrm{b}$, and $\mathrm{c}$ in $\mathrm{a}$ given column indicate significant differences at the 0.05 level by Tukey's test and analysis of variance (ANOVA)]

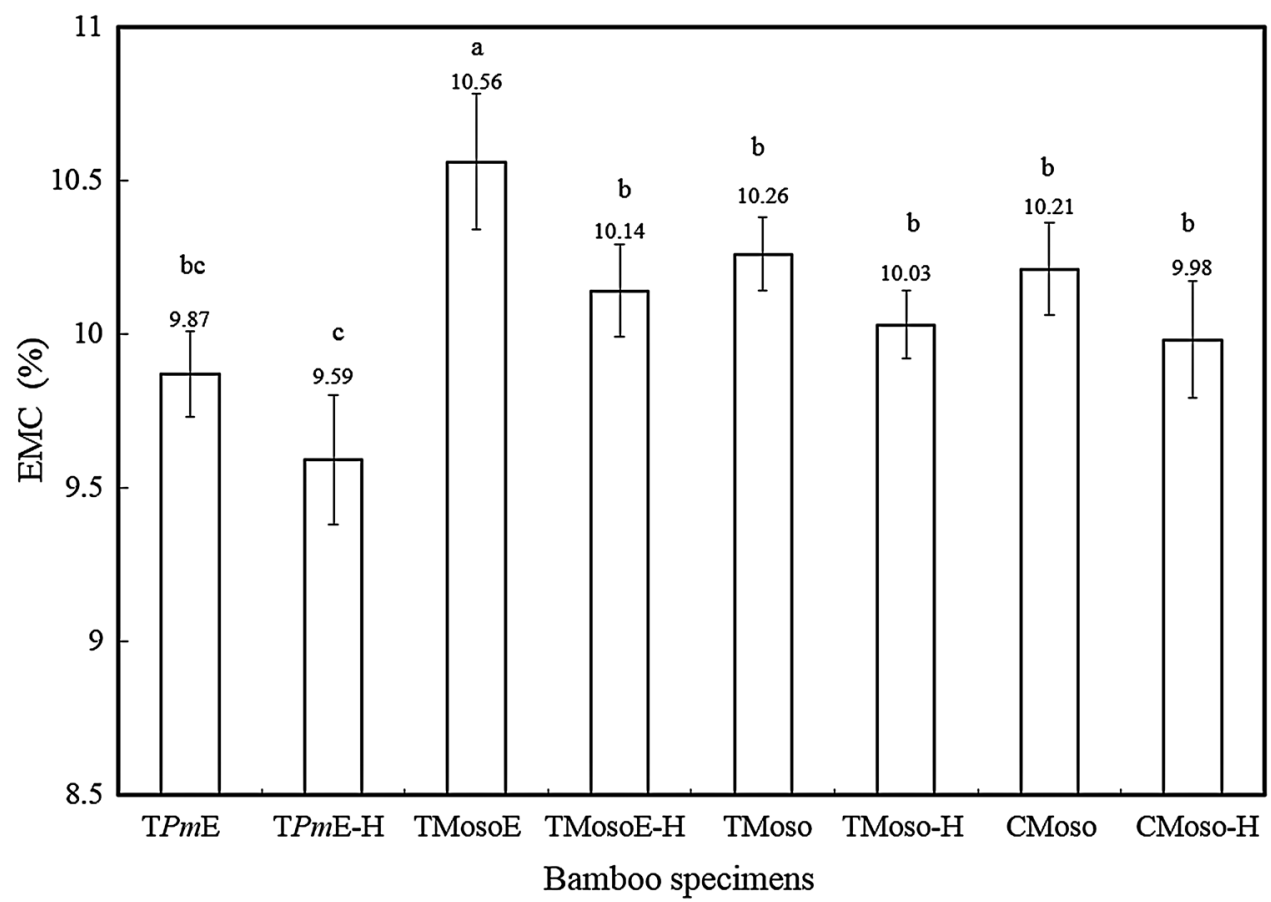

$\mathrm{H}<$ TMoso- $\mathrm{H}<\mathrm{T}$ PmE-H $<$ TMosoE-H (density values were $0.66,0.75,0.77$, and $0.80 \mathrm{~g} / \mathrm{cm}^{3}$, respectively); moreover, the density of SHT moso bamboo, which collected from China (CMoso-H), was the lowest. Compared with EPT specimens, those with intact epidermis had higher density, unpeeled moso bamboo showed the highest density among all specimens. The results obtained in this study demonstrated that both EPT and SHT would decrease bamboo density. The quality of timbers after thermal treatment had been studied well [28]. According to Mburu's finding, heat treatment would result in degradation of the wood composition and produce quality loss, and it would be coursed by different process, including temperature, processing time, and quality of the media. Related research had also reported that reduction in mechanical strength of plantation wood instigated by significant mass loss under heat treatment above $170{ }^{\circ} \mathrm{C}$ for more than $2 \mathrm{~h}$ [20].

\section{Equilibrium moisture content (EMC)}

The EMC of bamboo specimens was condition at constant temperature chamber, which was set the temperature at $20{ }^{\circ} \mathrm{C}$ and in a $65 \% \mathrm{RH}$ constant. Figure 5 shows the EMC of bamboo specimens, and it revealed a general trend of reduction in EMC after SHT for all specimens. EMC of untreated and SHT specimens were in the order of $\mathrm{TP} m \mathrm{E}<\mathrm{CMo}-$ so $<$ TMoso $<$ TMosoE (EMC values were 9.87, 10.21, 10.26 , and $10.56 \%$, respectively) and $\mathrm{TPmE}-\mathrm{H}<$ CMoso$\mathrm{H}<$ TMoso-H $<$ TMosoE-H (EMC values were 9.59, 9.98,
10.03 , and $10.14 \%$, respectively); SHT makino bamboo collected from Taiwan (TPmE-H) had the lowest EMC. Compared with EPT moso bamboo specimens, samples with intact epidermis had higher EMC. Among them, TMosoE presented the highest EMC (10.56\%). Taken together, the results indicated that both SHT and EPT reduced EMC.

\section{Mechanical properties}

Figure 6 illustrates the MOE and MOR of bamboos after EPT and/or SHT. As shown in Fig. 6, makino bamboo with intact epidermis had the highest MOE and MOR among the specimens whether SHT or not. The MOE and MOR of untreated moso bamboo specimens were in the order of TMosoE $>$ TMoso $>$ CMoso, while that of SHT samples were also in the same order of TMosoE-H $>$ TMoso$\mathrm{H}>\mathrm{CMoso}-\mathrm{H}$. Although the results showed no statistical significance $(p<0.05), \mathrm{MOE}$ and MOR tended to decrease after SHT for all specimens, exception for MOE of unpeeled makino bamboo (TPmE). The results revealed that EPT and SHT did affect mechanical strength of moso bamboo, while makino bamboo with intact epidermis could maintain high mechanical strength even when thermally treated.

Kocaefe et al. investigated the effect of heat treatment on the mechanical properties of jack pine (Pinus banksiana) in North America and found decreased in bending strength by heat treatment [29]. When drying of wood materials by heating treatment, significant changes in composition and structure of wood occurred under thermal 
Fig. $6 \mathrm{MOE}$ and MOR of eight different bamboo specimens [results are mean \pm SE, $n=9$; different letters $\mathrm{a}, \mathrm{b}$, and $\mathrm{c}$ in $\mathrm{a}$ given column indicate significant differences at the 0.05 level by Tukey's test and analysis of variance (ANOVA)]

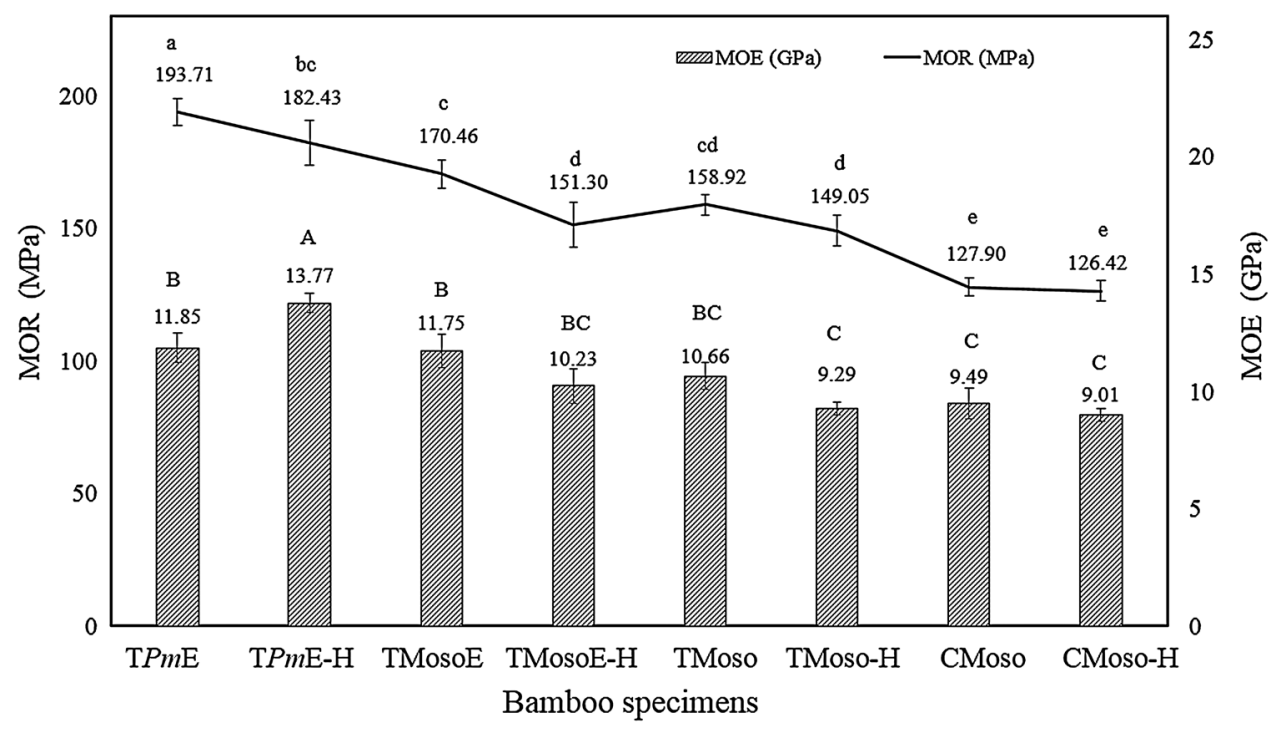

degradation at treatment temperature above $160{ }^{\circ} \mathrm{C}$. Madakadze et al. demonstrated that strength of paper varied with lignin and cellulose contents of raw plant materials [30]. In particular, tensile strength was directly related to cellulose content. Results on chemical properties had shown that makino bamboo contained more holocellulose and $\alpha$-cellulose than moso bamboo. Hence, makino bamboo should exhibit better mechanical strength than moso bamboo, as evidenced by the present results.

\section{Dimensional stability}

Previous studies had reported that heat treatment caused the changes of wood composition and structure, thus reducing volumetric swelling and hygroscopicity [31, 32]. These changes in turn contribute to improve the dimensional stability of woody materials.

\section{Thickness and volumetric swelling coefficient}

Figure 7 shows both thickness swelling coefficient (TS\%) and volumetric swelling coefficient $(\mathrm{S} \%)$ of the bamboo specimens after EPT and SHT. It revealed a general trend of decreasing in both TS\% and S\% after SHT. Moreover, the orders of TS\% in untreated and SHT were CMoso $<\mathrm{TMosoE}<\mathrm{TPmE}<\mathrm{TMoso}$ (TS values were 5.04, $6.24,8.62$, and $11.99 \%$, respectively) and CMoso$\mathrm{H}<\mathrm{TMosoE}-\mathrm{H}<\mathrm{TPmE}-\mathrm{H}<\mathrm{TMoso}-\mathrm{H}$ (TS values were $3.88,5.78,8.05$, and $8.11 \%$, respectively), while the $\mathrm{S} \%$ in untreated and SHT was in the order of CMoso $<\mathrm{TMosoE}<\mathrm{TMoso}<\mathrm{TPmE}$ ( $\mathrm{T} \%$ values were 8.81 , $12.50,15.61$, and $16.54 \%$, respectively) and CMoso$\mathrm{H}<\mathrm{TMosoE}-\mathrm{H}<\mathrm{TMoso}-\mathrm{H}<\mathrm{TPmE}-\mathrm{H} \quad(\mathrm{S} \% \quad$ values were $7.90,10.62,11.71$, and $16.35 \%$, respectively). Whether EPT treatment or not for China Moso Bamboo showed the least TS\% and S\% among the specimens. For the specimens from Taiwan, moso bamboo with intact epidermis presented lower $\mathrm{TS} \%$ and $\mathrm{S} \%$ than that with EPT. On the other hand, untreated moso bamboo with intact epidermis had the highest TS\% (11.99\%), and untreated makino bamboo with intact epidermis had the highest S\% (16.54\%). The results indicated that EPT had a negative effect on dimensional stability, while SHT had a positive efficiency. Yang et al. observed insignificant dimensional changes in both tangential and radial directions in moso bamboo [21]. It might due to bamboo have more vertical tissues than horizontal tissues. Water absorption eliminates traction in horizontal tissues, thus making dimensional changes in tangential and radial directions more significant. The $\mathrm{S} \%$ takes into account length, breadth, and thickness of the specimens; hence, it could be seen that S\% always exceeds TS\%.

\section{Water absorption}

Figure 8 shows water absorption percentage (WA\%) of the eight different bamboo specimens. Untreated bamboo specimens with intact epidermis had much higher WA\% than those EPT $(74.34 \%$ in TMoso and $72.18 \%$ in CMoso vs. $45.22 \%$ in $\mathrm{TPmE}$ and $43.14 \%$ in $\mathrm{TMosoE}$ ). It revealed that EPT enhanced the hydrophilicity in bamboo. Moreover, significant changes after SHT were observed only in EPT moso bamboo specimens. That was SHT markedly reduced the water absorption in EPT specimens. In contrast, changes in water absorption in intact skin of makino and moso bamboos were slight $(p<0.05)$. Mohebby and Ilbeighi attributed suppression in water absorption to increase in cellulose crystallinity and reduction in amorphous regions in cellulose microfibrils [33]. Observations in WA\% were consistent with the EMC analysis results 
Fig. 7 TS (\%) and S (\%) of eight different bamboo specimens [results are mean $\pm \mathrm{SE}, n=9$; different letters $\mathrm{a}, \mathrm{b}, \mathrm{c}, \mathrm{d}$, and $\mathrm{e}$ in a given column indicate significant differences at the 0.05 level by Tukey's test and analysis of variance (ANOVA)]
(\%)
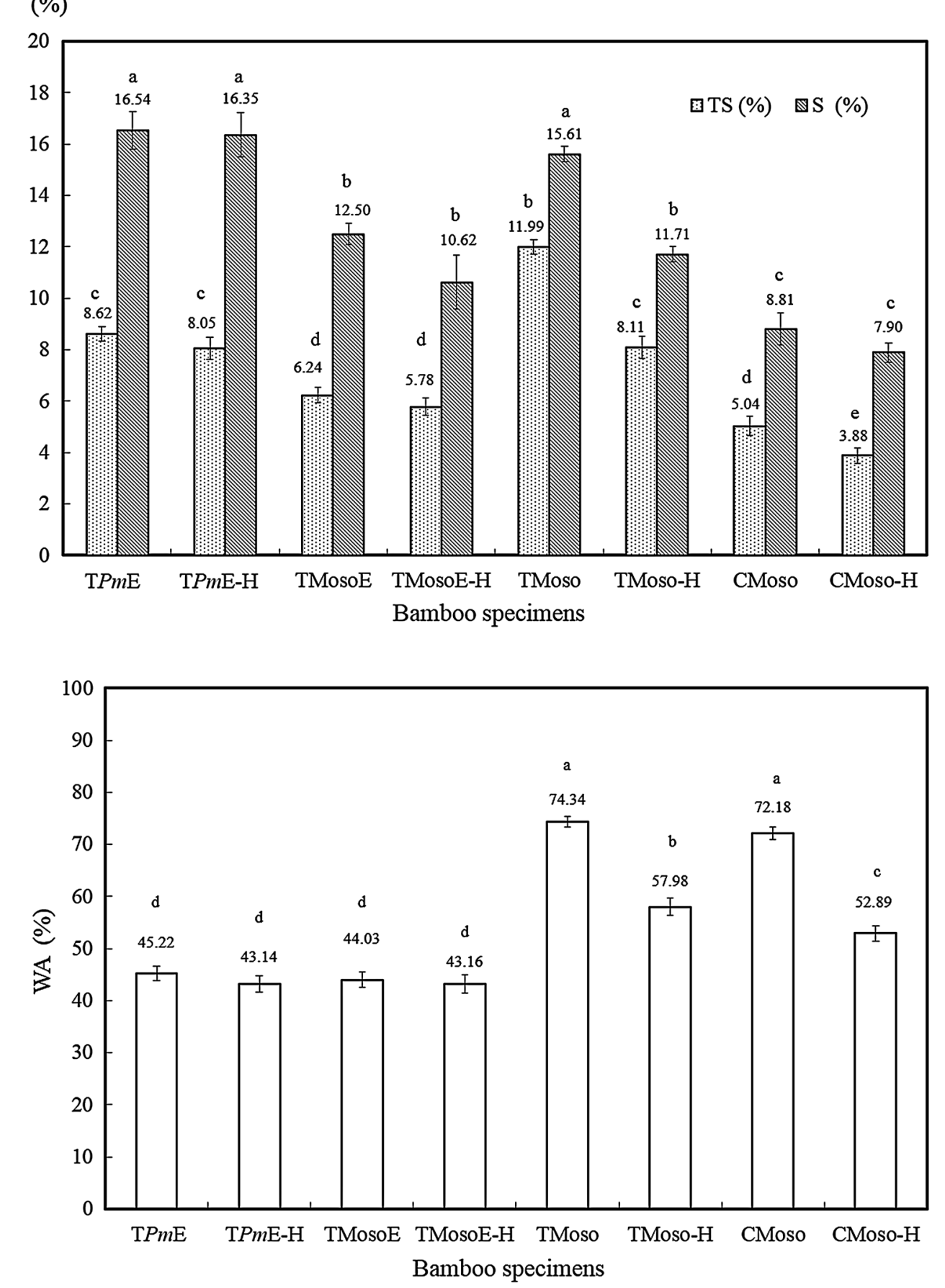

Fig. 8 WA (\%) of eight different bamboo specimens [results are mean $\pm \mathrm{SE}, n=9$; different letters $\mathrm{a}, \mathrm{b}, \mathrm{c}$, and $\mathrm{d}$ in a given column indicate significant differences at the 0.05 level by Tukey's test and analysis of variance (ANOVA)] reported above that SHT and EPT decreased hygroscopicity of bamboos.

\section{Conclusions}

The aim of this study was to evaluate effects of EPT and SHT on chemical, physical, and mechanical properties of makino and moso bamboo culms. Our results demonstrated a trend of incensement in extractives and ash contents after EPT and SHT, and SHT moso bamboo collected from China contained the highest amount of extractives and hemicellulose. Moreover, EPT and SHT would reduce all cellulose contents, though the differences were not significant. Makino bamboo contained more holocellulose and $\alpha$ cellulose and, however, less hemicellulose content than moso bamboo. Moso bamboo from Taiwan had higher cellulose content than that from China. Moso bamboo from 
China was found to have significant higher acid-soluble lignin content than those from Taiwan, and SHT has slight effect on the Klason lignin content of both moso and makino bamboo. Moreover, EPT and SHT reduced EMC and affected mechanical strength of moso bamboo, while makino bamboo with intact epidermis could maintain high mechanical strength even after SHT. EPT had a negative effect, while SHT had a positive effect on dimensional stability.

Acknowledgements This study was supported by a Grant (105-A015) from the Experimental Forest, College of Bioresource and Agriculture, National Taiwan University, Taiwan, ROC. We also thank the Forestry Bureau for financial support.

\section{References}

1. Sharma YML (1980) Bamboos in the Asia-Pacific region: bamboo research in Asia. IDRC, Ottawa

2. Lakkad SC, Patel JM (1981) Mechanical properties of bamboo, a natural composite. Fibre Sci Technol 14:319-322

3. Liese W (1987) Research on bamboo. Wood Sci Technol 21:189-209

4. Chang ST, Chang HT (2001) Comparisons of the photostability of esterified wood. Polym Degrad Stab 71:261-266

5. Evans PD, Owen NL, Schmid S, Webster RD (2002) Weathering and photostability of benzoylated wood. Polym Degrad Stab 76:291-303

6. Bekhta P, Niemz P (2003) Effect of high temperature on the change in color, dimensional stability and mechanical properties of spruce wood. Holzforschung 57:539-546

7. Borrega M, Kärenlampi PP (2008) Mechanical behavior of heattreated spruce (Picea abies) wood at constant moisture content and ambient humidity. Holz Roh Werkst 66:63-69

8. Esteves B, Pereira H (2009) Wood modification by heat treatment: a review. Bio Resources 4:370-404

9. Zhao RJ, Jiang ZH, Hse CY, Shupe TF (2010) Effects of steam treatment on bending properties and chemical composition of moso bamboo (Phyllostachys pubescens). J Trop Forest Sci 22:197-201

10. Yildiz S, Gezer ED, Yildiz UC (2006) Mechanical and chemical behavior of spruce wood modified by heat. Build Environ 41:1762-1766

11. Lee CH, Chung MJ, Lin CH, Yang TH (2012) Effects of layered structure on the physical and mechanical properties of laminated moso bamboo (Phyllosachys edulis) flooring. Constr Build Mater 28:31-35

12. ASTM D 1107-56 (1983) Standard test method for alcohol-benzene solubility of wood. American Society for Testing and Materials, Philadelphia

13. ASTM D 1104-56 (1978) Standard test method for holocellulose in wood. American Society for Testing and Materials, Philadelphia

14. ASTM D 1103-60 (1977) Standard test method for alpha-cellulose in wood. American Society for Testing and Materials, Philadelphia
15. ASTM D 1106-56 (1977) Standard test method for lignin in wood. American Society for Testing and Materials, Philadelphia

16. ASTM D 1106-96 (2001) Standard test method for acid-insoluble lignin in wood. American Society for Testing and Materials, West Conshohocken

17. ASTM D 1102-84 (2001) Standard test method for ash in wood. American Society for Testing and Materials, West Conshohocken

18. ASTM D 1037 (1999) Standard test method for evaluating properties of wood base fiber and particle panel materials. American Society for Testing Materials, West Conshohocken

19. Hon NS (2001) Wood and cellulosic chemistry. Marcel Dekker, Inc., New York

20. Lu SY, Cho CL (2014) Effects of heat treatment on the chemical properties of three domestic plantation wood species (in Chinese). Forest Prod Ind 33:13-26

21. Yang TH, Lee CH, Lee CJ, Cheng YW (2016) Effects of different thermal modification media on physical and mechanical properties of moso bamboo. Constr Build Mater 119:251-259

22. Candelier K, Dumarcay S, Pétrissans A, Desharnais L, Gérardin P, Pétrissans M (2013) Comparison of chemical composition and decay durability of heat treated wood cured under different atmospheres: nitrogen or vacuum. Polym Degrad Stab 98:677-681

23. Boonstra MJ, Tjeerdsma B (2006) Chemical analysis of heat treated softwoods. Holz Roh Werkst 64:204-211

24. Li XB, Shupe TF, Peter GF, Hse CY, Eberhardt TL (2007) Chemical changes with maturation of the bamboo species Phyllostachys pubescens. J Trop Forest Sci 19:6-12

25. Peng H, Wang N, Hu Z, Yu Z, Liu Y, Zhang J, Ruan R (2012) Physicochemical characterization of hemicelluloses from bamboo (Phyllostachys pubescens) stem. Ind Crop Prod 37:41-50

26. Brito JO, Silva FG, Leão MM, Almeida G (2008) Chemical composition changes in eucalyptus and pinus woods submitted to heat treatment. Bioresour Technol 99:8545-8548

27. Kartal SN, Hwang WJ, Imamura Y (2008) Combined effect of boron compounds and heat treatments on wood properties: chemical and strength properties of wood. J Mater Process Technol 198:234-240

28. Mburu F, Dumarcay S, Bocquet JF, Petrissans M, Gérardin P (2008) Effect of chemical modifications caused by heat treatment on mechanical properties of Grevillea robusta wood. Polym Degrad Stab 93:401-405

29. Kocaefe D, Poncsak S, Tang J, Bouazara M (2010) Effect of heat treatment on the mechanical properties of North American Jack Pine: thermo gravimetric study. J Mater Sci 45:681-687

30. Madakadze IC, Radiotis T, Li J, Goel K, Smith DL (1999) Kraft pulping characteristics and pulp properties of warm season grasses. Bioresource Technol 69:75-85

31. Gunduz G, Aydemir D (2009) Some physical properties of heattreated Hornbeam (Carpinus betulus L.) wood. Dry Technol 27:714-720

32. Korkut S, Bektas I (2008) The effects of heat treatment on physical properties of Uludag fir (Abies bornmuelleriana Mattf.) and Scots pine (Pinus sylvestris L.) wood. Forest Prod J 58:95-99

33. MohebbyB,Ilbeighi F (2007) Physical and mechanical properties of hydrothermally modified medium density fiberboard (MDF). Proceedings of the International Panel Products Symposium. Cardiff, Wales, UK 